\title{
Isolated severe blunt traumatic brain injury: effect of obesity on outcomes
}

\author{
Jennifer T. Cone, MD, MHS, ${ }^{1}$ Elizabeth R. Benjamin, MD, PhD, ${ }^{2}$ Daniel B. Alfson, MD, ${ }^{2}$ and \\ Demetrios Demetriades, MD, PhD²
}

1Department of Surgery, Section of Trauma and Acute Care Surgery, University of Chicago, Illinois; and 2Department of Surgery, Division of Trauma, Emergency Surgery, and Surgical Critical Care, LAC+USC Medical Center, University of Southern California, Los Angeles, California

OBJECTIVE Obesity has been widely reported to confer significant morbidity and mortality in both medical and surgical patients. However, contemporary data indicate that obesity may confer protection after both critical illness and certain types of major surgery. The authors hypothesized that this "obesity paradox" may apply to patients with isolated severe blunt traumatic brain injuries (TBIs).

METHODS The Trauma Quality Improvement Program (TQIP) database was queried for patients with isolated severe blunt TBI (head Abbreviated Injury Scale [AIS] score 3-5, all other body areas AIS < 3). Patient data were divided based on WHO classification levels for BMl: underweight $\left(<18.5 \mathrm{~kg} / \mathrm{m}^{2}\right)$, normal weight $\left(18.5-24.9 \mathrm{~kg} / \mathrm{m}^{2}\right)$, overweight $\left(25.0-29.9 \mathrm{~kg} / \mathrm{m}^{2}\right)$, obesity class $1\left(30.0-34.9 \mathrm{~kg} / \mathrm{m}^{2}\right)$, obesity class $2\left(35.0-39.9 \mathrm{~kg} / \mathrm{m}^{2}\right)$, and obesity class $3(\geq 40.0 \mathrm{~kg} /$ $\left.\mathrm{m}^{2}\right)$. The role of $\mathrm{BMI}$ in patient outcomes was assessed using regression models.

RESULTS In total, 103,280 patients were identified with isolated severe blunt TBI. Data were excluded for patients aged $<20$ or $>89$ years or with $\mathrm{BMI}<10$ or $>55 \mathrm{~kg} / \mathrm{m}^{2}$ and for patients who were transferred from another treatment center or who showed no signs of life upon presentation, leaving data from 38,446 patients for analysis. Obesity was not found to confer a survival advantage on univariate analysis. On multivariate analysis, underweight patients as well as obesity class 1 and 3 patients had a higher rate of mortality (OR 1.86, 95\% Cl 1.48-2.34; OR 1.18, 95\% Cl 1.01-1.37; and OR $1.41,95 \% \mathrm{Cl} 1.03-1.93$, respectively). Increased obesity class was associated with an increased risk of respiratory complications (obesity class 1 : OR $1.19,95 \% \mathrm{Cl} 1.03-1.37$; obesity class 2 : OR 1.30, $95 \% \mathrm{Cl} 1.05-1.62$; obesity class 3 : OR $1.55,95 \% \mathrm{Cl} 1.18-2.05$ ) and thromboembolic complications (overweight: OR 1.43, 95\% Cl 1.16-1.76; obesity class 1: OR $1.45,95 \% \mathrm{Cl} 1.11-1.88$; obesity class 2 : OR $1.55,95 \% \mathrm{Cl} 1.05-2.29)$ despite a decreased risk of overall complications (obesity class 2: OR $0.82,95 \% \mathrm{Cl} 0.73-0.92$; obesity class 3 : OR $0.83,95 \% \mathrm{Cl} 0.72-0.97$ ). Underweight patients had a significantly increased risk of overall complications (OR 1.39, 95\% Cl 1.24-1.57).

CONCLUSIONS Although there was an obesity-associated decrease in overall complications, the study data did not demonstrate a paradoxical protective effect of obesity on mortality after isolated severe blunt TBI. Obese patients with isolated severe blunt TBI are at increased risk of respiratory and venous thromboembolic complications. However, underweight patients appear to be at highest risk after severe blunt TBI, with significantly increased risks of morbidity and mortality.

https://thejns.org/doi/abs/10.3171/2020.3.JNS193458

KEYWORDS traumatic brain injury; blunt trauma; body mass index; obesity; TQIP; Trauma Quality Improvement Program

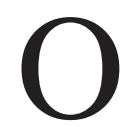
BESITY is a significant medical comorbidity that has risen dramatically in prevalence in the United States over the last several decades. The prevalence of obesity has more than doubled in the last 25 years. Currently, $36.5 \%$ of the US population is obese, with all states having an obesity prevalence of at least $20 \%$ (https:// www.cdc.gov/obesity/data/index.html).

Weight is standardly described by the World Health Organization in reference to a person's body mass index (BMI; $\left.\mathrm{kg} / \mathrm{m}^{2}\right){ }^{1}$ Obesity is a BMI $\geq 30 \mathrm{~kg} / \mathrm{m}^{2}$, with the fol-

ABBREVIATIONS AIS = Abbreviated Injury Scale; ALI/ARDS = acute lung injury/acute respiratory distress syndrome; $A$ UROC $=$ area under the receiver operating characteristic; DVT = deep venous thrombosis; ED = emergency department; GCS = Glasgow Coma Scale; HR = heart rate; LOS = length of stay; PE = pulmonary embolism; SBP = systolic blood pressure; TBI = traumatic brain injury; TQIP = Trauma Quality Improvement Program; UTI = urinary tract infection; VTE = venous thromboembolism. SUBMITTED December 20, 2019. ACCEPTED March 9, 2020.

INCLUDE WHEN CITING Published online June 12, 2020; DOI: 10.3171/2020.3.JNS193458. 
lowing discrete obesity classes for increasing BMI: normal weight, $18.5-24.9 \mathrm{~kg} / \mathrm{m}^{2}$; underweight, $<18.5 \mathrm{~kg} / \mathrm{m}^{2}$; and overweight, $25.0-29.9 \mathrm{~kg} / \mathrm{m}^{2}$. Because BMI is not a measure of body fat, there is some controversy regarding its utility, especially in individuals with high muscle mass. ${ }^{2}$ Despite this, BMI remains a standard variable in the description and study of weight.

It is generally believed that obesity carries a substantial risk for increased morbidity and mortality in the general population. ${ }^{3-6}$ Despite this intuitive assumption, there is recent evidence that obese patients may have improved outcomes in certain clinical scenarios..$^{713}$ This protective effect of obesity has been described as the "obesity paradox." This term was first coined in 2002 after Gruberg et al. showed that normal-weight patients fared worse after percutaneous coronary intervention than overweight and obese patients, and since then the obesity paradox has been examined in a wide range of medical and surgical patient populations. ${ }^{14}$ Studies have documented this phenomenon in cases of infection and cancer, as well as after cardiac surgery, general surgery, and vascular surgery. 7,8 , ${ }^{14-17,19,20,37}$ Although the etiology of this paradoxical finding is unclear, it is thought to be based in an antiinflammatory effect conferred by the adipose tissue. ${ }^{21-23}$

The study of the obesity paradox in the trauma population has yielded conflicting results, likely due to the heterogeneity of the population. ${ }^{18,24-31}$ Patients with isolated severe blunt traumatic brain injury (TBI) represent a clinically unique subset of the trauma population, and the effect of obesity on outcomes in these patients is unclear. In this study we aimed to determine the effect of patient BMI on outcomes after isolated severe blunt TBI.

\section{Methods}

This study was a retrospective analysis of patient data obtained from the Trauma Quality Improvement Program (TQIP) database. Data for all adult patients with isolated severe blunt TBI were collected (2013-2014). Isolated severe blunt TBIs were defined based on a head Abbreviated Injury Scale (AIS) score of 3-5. Patients with significant extracranial injuries (AIS > 2) were excluded (Fig. 1). Other exclusion criteria included patients aged $<20$ years or $>89$ years and patients who were dead on arrival. Patients who were transferred from another hospital were also excluded, as initial data for vital signs and Glasgow Coma Scale (GCS) scores recorded at an outside hospital could not be accurately abstracted. Pertinent demographic and clinical data for each patient were extracted, including age, sex, height, weight, comorbidities (including hypertension, smoking status, diabetes mellitus, alcoholism, and bleeding disorder), initial emergency department (ED) vital signs and GCS scores, hospital length of stay (LOS), ICU LOS, presence of and time to venous thromboembolism (VTE) prophylaxis, in-hospital complications, and mortality. Data were collected for in-hospital complications, including pneumonia, acute lung injury/acute respiratory distress syndrome (ALI/ARDS), unplanned intubation, deep venous thrombosis (DVT), thrombophlebitis, pulmonary embolism (PE), urinary tract infection (UTI), and myocardial infarction, as well as mortality. BMI was cal-

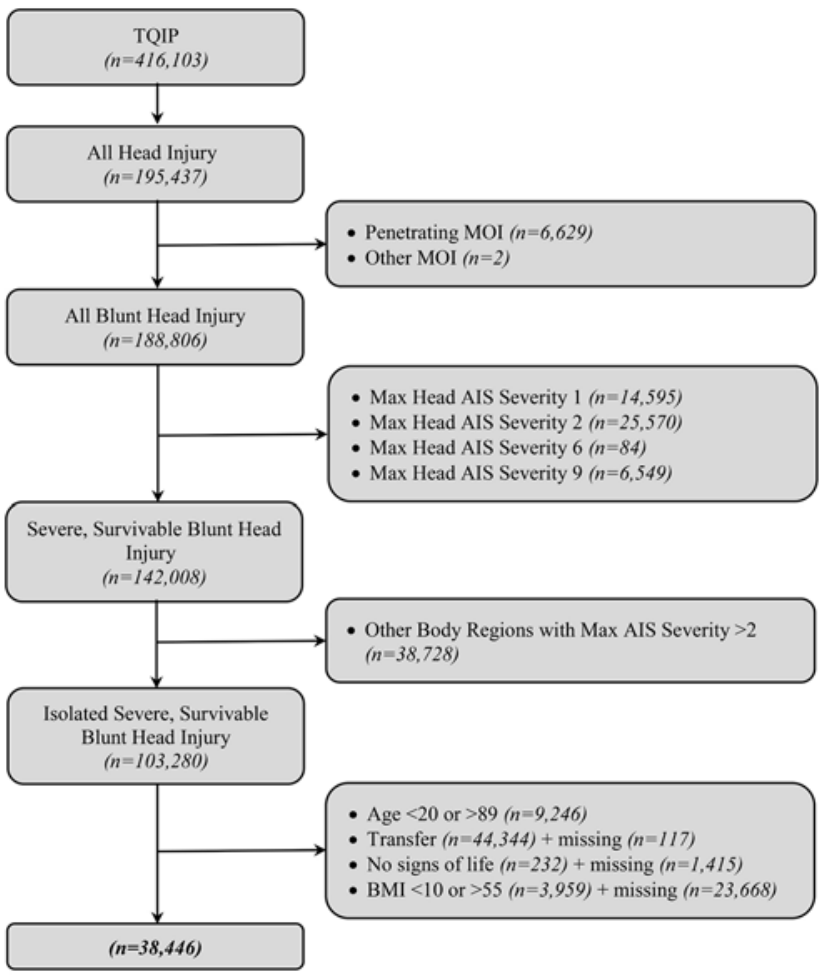

FIG. 1. Study design. All patients recorded in the TQIP database with isolated severe blunt TBI indicated by maximum (Max) AIS scores of 3 $(n=37,786), 4(n=76,856)$, or $5(n=27,366)$ were selected, leaving data from 38,446 patients for analysis after exclusion criteria were applied (some patients met multiple exclusion criteria). $\mathrm{MOI}=$ mechanism of injury.

culated using the standard formula. ${ }^{1}$ Patients with BMI < 10 or $>55 \mathrm{~kg} / \mathrm{m}^{2}$ were excluded. Patients were then stratified into 5 groups according to their BMI classification: underweight $\left(<18.5 \mathrm{~kg} / \mathrm{m}^{2}\right)$, normal weight (18.5-24.9 kg/ $\mathrm{m}^{2}$ ), overweight $\left(25.0-29.9 \mathrm{~kg} / \mathrm{m}^{2}\right)$, obesity class $1(30.0-$ $\left.34.9 \mathrm{~kg} / \mathrm{m}^{2}\right)$, obesity class $2\left(35.0-39.9 \mathrm{~kg} / \mathrm{m}^{2}\right)$, and obesity class $3\left(\geq 40.0 \mathrm{~kg} / \mathrm{m}^{2}\right)$.

The primary outcomes were overall mortality and overall in-hospital complications. Secondary outcomes included occurrence of any respiratory complications (including ALI/ARDS, pneumonia, and unplanned intubation) and occurrence of any VTE complications (including DVT and PE).

Unknown data points were treated as missing data. Descriptive and comparative statistical analyses were performed, with categorical data reported as number $(\%)$ and nonparametric continuous variables reported as medians with interquartile ranges (IQRs), as well as dichotomized into clinically relevant cutoff values. Univariate analysis for categorical variables was performed using the chisquare test or the Fisher exact test and for continuous variables the Kruskal-Wallis test.

To compare outcomes according to BMI group, binomial logistic regression models were constructed using normal-weight patients as the reference group, with variables inserted using the enter method. Demographic and clinical variables-including male sex; age $>55$ years; 
maximum head AIS scores of 3, 4, or 5; systolic blood pressure (SBP) < $90 \mathrm{~mm} \mathrm{Hg}$; heart rate (HR) > 120 bpm; GCS score < 9; and presence of any comorbidity-were used as controlling variables. Variables were chosen for clinical relevance associated with outcomes of interest. Results were presented as adjusted odds ratios (ORs) with 95\% confidence intervals (CIs) and $\mathrm{p}$ values. The accuracy of each regression model was assessed by reporting the chi-square value and plotting area under the receiver operating characteristic (AUROC) curve graphs with 95\% CIs.

A subgroup analysis was then performed for each individual AIS score of 3-5, using the same groups, variables, and statistical analyses detailed above.

The level of statistical significance for all tests was set at $\mathrm{p}<0.05$, and all $\mathrm{p}$ values are 2-tailed. SPSS for Mac (version 23, IBM Corp.) was used for all statistical analyses.

\section{Results}

In total, 38,446 patients with severe isolated blunt TBI met criteria for analysis (Fig. 1). On admission, the majority of patients were hemodynamically stable $(98.9 \%$, $\mathrm{n}=38,032)$. Only $12.4 \%(\mathrm{n}=4782)$ of patients presented with a GCS score $<9$. Normal and overweight BMIs were most common $(39.7 \%, \mathrm{n}=15,275$; and $34.0 \%, \mathrm{n}=$ 13,086 , respectively). The majority of patients had at least one comorbidity $(79.1 \%, \mathrm{n}=30,403)$, most commonly hypertension, history of smoking, and diabetes mellitus $(39.5 \%, \mathrm{n}=15,184 ; 18.2 \%, \mathrm{n}=6993$; and $15.7 \%, \mathrm{n}=6027$, respectively). Obese patients had higher rates of hypertension $(46.1 \%, \mathrm{n}=2583 ; 51.3 \%, \mathrm{n}=979$; and $50.4 \%, \mathrm{n}=521$ for obesity classes 1,2 , and 3 , respectively) and diabetes $(22.4 \%, \mathrm{n}=1256 ; 29.0 \%, \mathrm{n}=553$; and $30.7 \%, \mathrm{n}=317$ for obesity classes 1,2 , and 3 , respectively). Underweight and normal-weight patients were more likely to be smokers $(21.6 \%, \mathrm{n}=333$, and $21.2 \%, \mathrm{n}=3238$, respectively) and have alcoholism $(15.6 \%, \mathrm{n}=240$, and $16.7 \%, \mathrm{n}=2558$, respectively; Table 1).

\section{Univariate Analysis}

Overall mortality was $6.7 \%(\mathrm{n}=2563)$, with the highest mortality rates in the underweight population $(9.9 \%, \mathrm{n}=$ 152). The overall in-hospital complication rate was $30.0 \%$ $(\mathrm{n}=11,518)$, with the lowest rates in patients with class 2 or 3 obesity $(26.7 \%, \mathrm{n}=510$, and $26.4 \%, \mathrm{n}=273$, respectively). The most common complications were respiratory $(5.5 \%, \mathrm{n}=2132)$, with $4.2 \%$ of patients developing pneumonia $(\mathrm{n}=1609)$. VTE complications were uncommon, at $1.4 \%$ overall $(\mathrm{n}=556)$; PE $0.3 \%(\mathrm{n}=113)$; and DVT $1.2 \%$ $(\mathrm{n}=477)$. Time to VTE prophylaxis (median 3 days) was the same across all patient groups (Table 1).

\section{Multivariate Analysis}

On multivariate analysis, underweight patients as well as obesity class 1 and 3 patients had significantly increased mortality compared with normal-weight patients (OR 1.86 [95\% CI 1.48-2.34], OR 1.18 [95\% CI 1.01-1.37], and OR 1.41 [95\% CI 1.03-1.93], respectively; Table 2, Fig. 2). Conversely, obesity classes 2 and 3 were associated with significantly decreased risks for overall complications (OR
0.82 [95\% CI 0.73-0.92] and OR 0.83 [95\% CI 0.72-0.97], respectively). This advantage, however, was not evident in respiratory or VTE complications. When we evaluated the risk of respiratory complications, we observed a significantly increased risk for all obesity classes (obesity class 1, OR 1.19 [95\% CI 1.03-1.37]; obesity class 2, OR 1.30 [95\% CI 1.05-1.62]; and obesity class 3, OR 1.55 [95\% CI 1.18-2.05]). Furthermore, a significantly increased risk for VTE complications was seen in overweight patients (OR 1.43 [95\% CI 1.16-1.76]), as well as in patients with obesity class 1 (OR 1.45 [95\% CI 1.11-1.88]) or class 2 (OR 1.55 [95\% CI 1.05-2.29]). Multivariate analysis revealed a significantly increased risk for overall in-hospital complications in underweight patients compared with normalweight patients (OR 1.39 [95\% CI 1.24-1.57]; Table 2).

\section{Subgroup Analysis}

Subgroup analysis performed based on head AIS score showed similar mortality rates across obesity class regardless of head injury severity. The decreased risk of overall complications with increased BMI was most evident in the patients with AIS 3 head injury (OR 0.78 [95\% CI 0.670.91 ], 0.66 [95\% CI $0.52-0.83$ ], and 0.66 [95\% CI $0.49-$ $0.90]$ for obesity classes 1,2, and 3, respectively; Table 3).

\section{Discussion}

The obesity paradox, with improved outcomes in obese patients, has been shown to be present in many different medical and surgical patient populations. The present analysis shows that this paradox does not hold for mortality after severe blunt TBI. Obesity may be protective for complications overall; however, these data suggest that obesity is a significant risk factor for VTE and respiratory complications after severe TBI. As with similar BMIbased analyses performed after trauma or intervention, the underweight population had significantly higher mortality and complication rates than the normal-weight population.

Despite the significant amount of literature in support of the obesity paradox, there is no clear consensus regarding the correlation between obesity and mortality after TBI. In an NSQIP (National Surgical Quality Improvement Program) analysis of patients undergoing emergency surgery, obesity was found to be protective against mortality, a finding supported in the postsurgical and interventional literature. ${ }^{7,8,14}$ In the trauma-specific population, however, this paradox is less well supported. A study by Brown et al. showed a trend toward increased mortality in obese patients, with stepwise logistical regression showing obesity to be an independent risk factor for mortality, but higher BMI values were not associated with higher mortality. ${ }^{24}$ Conversely, Newell et al. found no correlation between morbid obesity and increased mortality (OR 0.810 [95\% CI 0.353-1.856]). ${ }^{32}$ In their meta-analysis that included patients with a penetrating mechanism of injury, Liu et al. demonstrated obesity as a risk factor for mortality (OR 2.02 [95\% CI 1.69-2.40]) but not for patients with an Injury Severity Scale score $\geq 15$ (OR 1.01 [95\% CI 0.79-1.27]). ${ }^{18}$ The data in these studies were similarly distributed, with small trends identified on statistical analysis but no clear consistent correlation between mortality and obesity. 


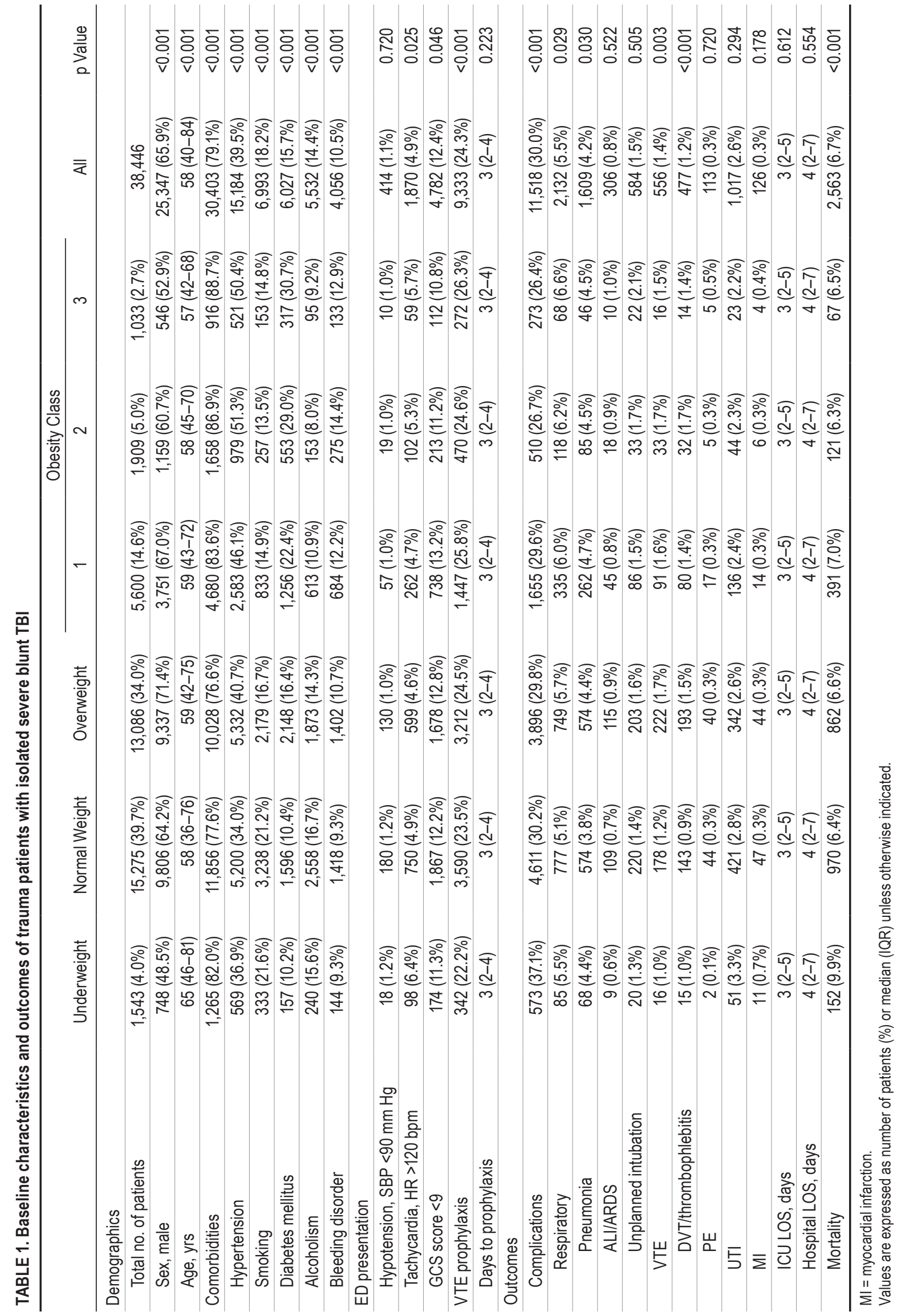


TABLE 2. Association between BMI classification and outcomes in trauma patients with isolated severe blunt TBI

\begin{tabular}{|c|c|c|c|c|c|c|}
\hline & \multirow[b]{2}{*}{ Underweight } & \multirow[b]{2}{*}{ Normal Weight } & \multirow[b]{2}{*}{ Overweight } & \multicolumn{3}{|c|}{ Obesity Class } \\
\hline & & & & 1 & 2 & 3 \\
\hline Mortality $(A)^{*}$ & $1.86(1.48-2.34)$ & Ref & $1.02(0.90-1.15)$ & $1.18(1.01-1.37)$ & $1.11(0.87-1.42)$ & $1.41(1.03-1.93)$ \\
\hline$p$ value & $<0.001$ & & 0.755 & 0.033 & 0.399 & 0.035 \\
\hline Complications, any (B) & $1.39(1.24-1.57)$ & Ref & $0.98(0.93-1.04)$ & $0.96(0.89-1.03)$ & $0.82(0.73-0.92)$ & $0.83(0.72-0.97)$ \\
\hline$p$ value & $<0.001$ & & 0.541 & 0.210 & $<0.001$ & 0.018 \\
\hline Complications, respiratory (C)† & $1.17(0.91-1.50)$ & Ref & $1.10(0.99-1.24)$ & $1.19(1.03-1.37)$ & $1.30(1.05-1.62)$ & $1.55(1.18-2.05)$ \\
\hline$p$ value & 0.225 & & 0.083 & 0.019 & 0.018 & 0.002 \\
\hline Complications, VTE (D)‡ & $0.90(0.52-1.56)$ & Ref & $1.43(1.16-1.76)$ & $1.45(1.11-1.88)$ & $1.55(1.05-2.29)$ & $1.56(0.92-2.63)$ \\
\hline$p$ value & 0.698 & & 0.001 & 0.006 & 0.029 & 0.989 \\
\hline
\end{tabular}

Values are expressed as adjusted $\mathrm{OR}(95 \% \mathrm{Cl})$ unless otherwise indicated. Boldface type indicates statistical significance.

* Logistic regression models adjusted for male sex, age $>55$ years, hypotension, tachycardia, GCS score < 9 , and presence of any comorbidity. Model performance: (A) $n=35,997$, AUROC 0.897 (95\% Cl 0.890-0.904), chi-square 6173.2 ( $p<0.001$ ); (B) $n=35,559$, AUROC 0.627 (95\% Cl 0.621-0.633), chi-square 1610.0 ( $<<0.001$ ); (C) $n=35,559$, AUROC 0.784 (95\% Cl 0.773-0.794), chi-square 2014.9 ( $p<0.001)$; (D) $n=35,559$, AUROC 0.723 (95\% Cl 0.700-0.746), chi-square 347.2 ( $<<0.001$ ). † Respiratory complications: ALI/ARDS, pneumonia, and unplanned intubation.

‡ VTE complications: DVT/thrombophlebitis and PE.

Despite a decrease in overall complications after severe TBI in obese patients, the rates of respiratory and VTE complications were noted to be higher. In 2005, Brown et al. showed that obesity is negatively associated with complications after blunt trauma, with complication rates of $42 \%$ in obese versus $32 \%$ in normal-weight patients $(p=0.002) .{ }^{24}$ Obese patients had longer ventilation time requirements and more frequent failed extubation. Newell et al. reported a similar result in their 2007 article: obesity was more frequently associated with respiratory complications, thrombosis, multisystem organ failure, and infection. ${ }^{32}$ The increased risk of DVT in obese patients after severe TBI is consistent with the described association with obesity overall and the known risk of DVT after TBI. ${ }^{1,33}$

Obese and overweight patients are known to have more comorbidities, such as diabetes, hypertension, heart disease, and sleep apnea. ${ }^{6,34-36}$ These factors likely predispose obese patients to higher rates of complications following traumatic events. However, the role of obesity in mortality is less well defined..$^{18,24,32}$ It has been posited that fat contains protective factors, such as upregulated TNF (tumor necrosis factor) and interleukin- 6 receptors that may decrease the inflammatory burden in these patients and

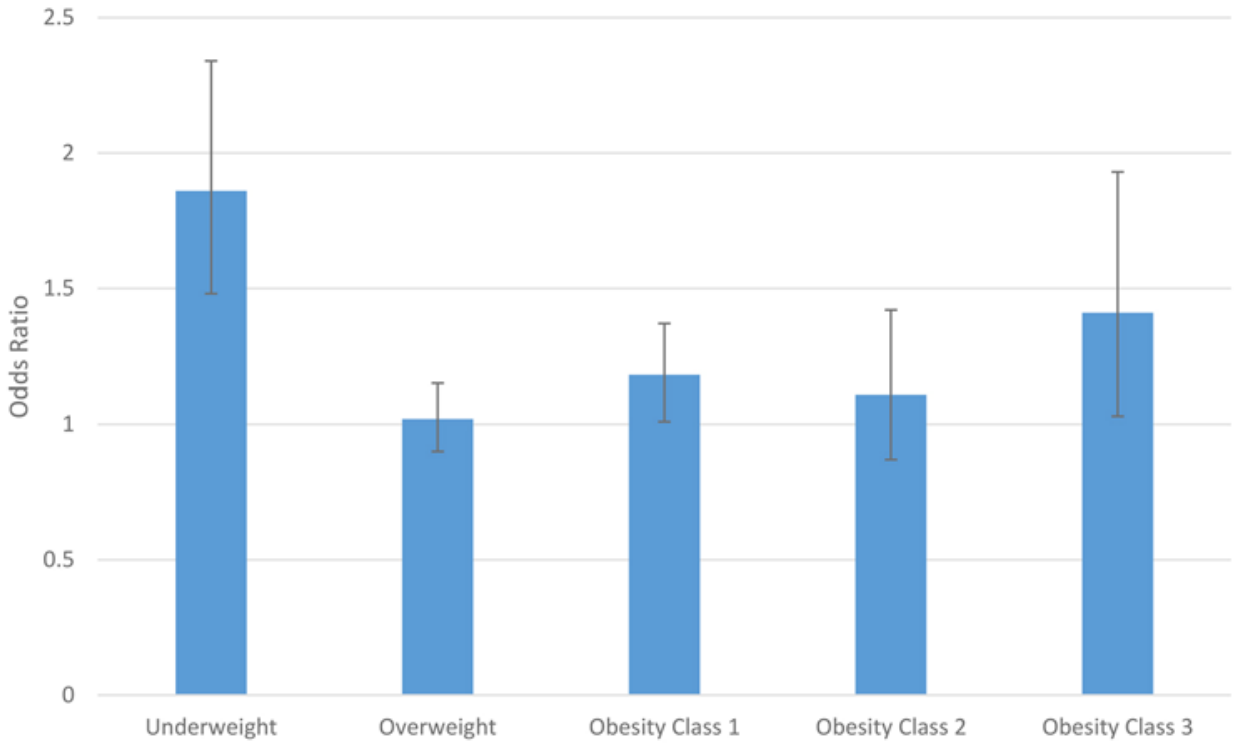

FIG. 2. ORs of mortality among weight categories. Values are expressed as adjusted $\mathrm{OR}(95 \% \mathrm{Cl})$. Logistic regression models were adjusted for male sex, age $>55$ years, hypotension, tachycardia, GCS score $<9$, presence of any comorbidity, and maximum head AIS severity score. Model performance: $n=35,997$, AUROC $0.897(95 \% \mathrm{Cl} 0.890-0.904)$, chi-square $6173.2(p<0.001)$. Figure is available in color online only. 
TABLE 3. Association between BMI classification and outcomes in patients with isolated severe blunt TBI: AIS subgroup analysis

\begin{tabular}{|c|c|c|c|c|c|c|}
\hline & \multirow[b]{2}{*}{ Underweight } & \multirow[b]{2}{*}{ Normal Weight } & \multirow[b]{2}{*}{ Overweight } & \multicolumn{3}{|c|}{ Obesity Class } \\
\hline & & & & 1 & 2 & 3 \\
\hline \multicolumn{7}{|l|}{ Maximum AIS $3(n=10,326)$} \\
\hline Mortality $(A)^{*}$ & $1.90(0.72-5.03)$ & Ref & $1.03(0.59-1.78)$ & $0.99(0.49-1.97)$ & $0.96(0.33-2.76)$ & $1.82(0.63-5.32)$ \\
\hline$p$ value & 0.198 & & 0.925 & 0.696 & 0.933 & 0.271 \\
\hline Complications, any (B) & $1.50(1.18-1.91)$ & Ref & $0.99(0.88-1.10)$ & $0.78(0.67-0.91)$ & $0.66(0.52-0.83)$ & $0.66(0.49-0.90)$ \\
\hline$p$ value & 0.001 & & 0.794 & 0.001 & $<0.001$ & 0.009 \\
\hline Complications, respiratory (C) & $1.32(0.59-2.99)$ & Ref & $1.07(0.74-1.56)$ & $0.67(0.39-1.15)$ & $0.67(0.28-1.58)$ & $1.50(0.66-3.41)$ \\
\hline$p$ value & 0.502 & & 0.712 & 0.146 & 0.357 & 0.328 \\
\hline Complications, VTE (D) & $1.85(0.54-6.34)$ & Ref & $1.16(0.62-2.18)$ & $1.15(0.52-2.55)$ & $2.49(1.04-5.99)$ & $0.68(0.09-5.14)$ \\
\hline$p$ value & 0.327 & & 0.635 & 0.735 & 0.041 & 0.710 \\
\hline \multicolumn{7}{|l|}{ Maximum AIS $4(n=21,579)$} \\
\hline Mortality (E) & $1.79(1.23-2.60)$ & Ref & $0.86(0.70-1.07)$ & $0.88(0.67-1.16)$ & $1.12(0.74-1.70)$ & $1.49(0.91-2.42)$ \\
\hline$p$ value & 0.003 & & 0.181 & 0.371 & 0.581 & 0.111 \\
\hline Complications, any (F) & $1.38(1.18-1.61)$ & Ref & $0.98(0.91-1.05)$ & $0.99(0.90-1.09)$ & $0.81(0.69-0.95)$ & $0.94(0.77-1.14)$ \\
\hline$p$ value & $<0.001$ & & 0.502 & 0.887 & 0.007 & 0.521 \\
\hline Complications, respiratory (G) & $1.25(0.86-1.81)$ & Ref & $1.13(0.96-1.33)$ & $1.19(0.97-1.47)$ & $1.46(1.07-2.00)$ & $1.77(1.21-2.60)$ \\
\hline$p$ value & 0.245 & & 0.149 & 0.097 & 0.017 & 0.003 \\
\hline Complications, VTE (H) & $0.68(0.27-1.68)$ & Ref & $1.59(1.18-2.15)$ & $1.24(0.83-1.84)$ & $1.19(0.63-2.25)$ & $1.79(0.89-3.61)$ \\
\hline$p$ value & 0.401 & & 0.002 & 0.293 & 0.599 & 0.104 \\
\hline \multicolumn{7}{|l|}{ Maximum AIS $5(n=6541)$} \\
\hline Mortality (I) & $1.89(1.40-2.57)$ & Ref & $1.11(0.96-1.29)$ & $1.38(1.14-1.67)$ & $1.11(0.81-1.52)$ & $1.25(0.81-1.94)$ \\
\hline$p$ value & $<0.001$ & & 0.165 & 0.001 & 0.507 & 0.313 \\
\hline Complications, any (J) & $1.37(1.05-1.77)$ & Ref & $1.02(0.90-1.15)$ & $1.10(0.93-1.29)$ & $1.09(0.84-1.40)$ & $0.80(0.55-1.15)$ \\
\hline$p$ value & 0.018 & & 0.808 & 0.261 & 0.527 & 0.227 \\
\hline Complications, respiratory $(\mathrm{K}) \dagger$ & $1.10(0.76-1.59)$ & Ref & $1.14(0.96-1.35)$ & $1.33(1.08-1.65)$ & $1.37(0.98-1.90)$ & $1.38(0.87-2.19)$ \\
\hline$p$ value & 0.620 & & 0.126 & 0.008 & 0.063 & 0.167 \\
\hline Complications, VTE (L)‡ & $0.92(0.39-2.15)$ & Ref & $1.33(0.95-1.87)$ & $1.84(1.24-2.74)$ & $1.68(0.91-3.09)$ & $1.59(0.67-3.77)$ \\
\hline$p$ value & 0.847 & & 0.096 & 0.003 & 0.099 & 0.292 \\
\hline
\end{tabular}

Values are expressed as adjusted OR $(95 \% \mathrm{Cl})$ unless otherwise indicated. Boldface type indicates statistical significance.

* Logistic regression models adjusted for male sex, age $>55$ years, hypotension, tachycardia, GCS score < 9 , presence of any comorbidity, and maximum head AIS score. Model performance: $(A) n=9719$, AUROC 0.723 (95\% Cl 0.670-0.775), chi-square 71.3 ( $p<0.001) ;(B) n=9594, A U R O C 0.590$ (95\% CI 0.577-0.603), chi-square 212.0 ( $p<0.001) ;(C) n=9594$, AUROC 0.770 (95\% Cl 0.730-0.810), chi-square 182.6 ( $p<0.001) ;(D) n=9594, A U R O C ~ 0.691$ (95\% Cl 0.625-0.758), chi-square 39.3 ( $<<0.001) ;(E) n=20,241$, AUROC 0.773 (95\% Cl 0.753-0.793), chi-square $680.7(p<0.001) ;(F) n=19,979, A U R O C 0.587(95 \%$ Cl 0.578-0.596), chi-square 483.6 ( $p<0.001) ;(G) n=19,979$, AUROC 0.714 (95\% Cl 0.695-0.773), chi-square 675.1 ( $p<0.001) ;(H) n=19,979, A U R O C$ 0.681 (95\% Cl 0.646-0.716), chi-square 113.9 ( $p<0.001) ;(I) n=6037$, AUROC 0.779 (95\% Cl 0.766-0.792), chi-square $1319.6(p<0.001) ;(J) n=5986, A U R O C 0.587(95 \%$ Cl 0.573-0.602), chi-square $147.4(p<0.001) ;(K) n=5986$, AUROC $0.625(95 \%$ Cl 0.605-0.645), chi-square $167.1(p<0.001) ;(L) n=5986, A U R O C$ 0.656 (95\% Cl 0.619-0.693), chisquare $61.8(p<0.001)$.

† Respiratory complications: ALI/ARDS, pneumonia, and unplanned intubation. ‡ VTE complications: DVT/thrombophlebitis and PE.

play a role in decreasing mortality. ${ }^{21-23}$ According to this reasoning, it could be postulated that a decreased inflammatory state could improve outcome after severe TBI, whereas stimulation of inflammatory processes could lead to secondary brain injury and worse outcomes. The current study data do not clearly support this theory, however. Even on subgroup analyses, no correlation between obesity and mortality was identified, and although the rates of respiratory and venous thromboembolic complications were higher in obese patients, overall complication rates were lower.

Our study did show increased risks of mortality for patients at the extremes of weight, those underweight and those severely obese. These patients also had higher incidences of comorbidities, namely smoking and alcoholism in underweight patients and hypertension and diabetes mellitus in class 3 obesity patients. It is certainly possible that there are modifiable risk factors, like delirium tremens management, glucose management, blood pressure control, and nutritional support, which would affect mortality in this patient population. The TQIP database does not allow this level of detail in the data; however, this is certainly a potential avenue for future studies.

There are several limitations to our study. First, it is a large-database retrospective study and as such may include inherent errors due to confounding and bias. Most 
importantly, institution-specific practices and regional variations are difficult to correct for. Moreover, the TQIP database does not capture physiological data such as intracranial pressure or cerebral perfusion pressure, so we were unable to determine the role obesity played in outcomes for these variables and their effects on mortality. Despite these shortcomings, however, this database provides a large, well-monitored data repository from which to determine trends, and these data represent, to our knowledge, the largest examination of the effect of BMI on outcomes after severe TBI. In addition, the underweight population is a small and diverse population. Without additional information to stratify this group reliably, it is difficult to interpret and draw significant conclusions. Our patients were grouped based on injury pattern and severity and therefore not perfectly matched, thus introducing the possibility of confounders in our results. Comorbidities such as smoking, hypertension, and diabetes mellitus all likely play a role in the morbidity and mortality of these patients and are likely underappreciated in the results. Finally, these data lack biological data regarding the posttraumatic inflammatory state of the patient. Prospective data including these elements in the trauma population will be an important addition to the literature to better understand the role of BMI on outcome in the severely injured patient.

\section{Conclusions}

These data suggest that obesity is not protective for mortality after severe blunt TBI and, although overall complications may be decreased with increasing obesity, rates of respiratory and venous thromboembolic events are significantly higher in the obese population. Underweight patients had both increased mortality and increased overall complications compared with normal-weight patients.

\section{References}

1. Ageno W, Becattini C, Brighton T, et al. Cardiovascular risk factors and venous thromboembolism: a meta-analysis. Circulation. 2008;117(1):93-102.

2. Abramowitz MK, Hall CB, Amodu A, et al. Muscle mass, BMI, and mortality among adults in the United States: a population-based cohort study. PLoS One. 2018;13(4):e0194697.

3. Berrington de Gonzalez A, Hartge P, Cerhan JR, et al. Bodymass index and mortality among 1.46 million white adults. $N$ Engl J Med. 2010;363(23):2211-2219.

4. Calle EE, Thun MJ, Petrelli JM, et al. Body-mass index and mortality in a prospective cohort of U.S. adults. $N$ Engl J Med. 1999;341(15):1097-1105.

5. Harris T, Cook EF, Garrison R, et al. Body mass index and mortality among nonsmoking older persons. The Framingham Heart Study. JAMA. 1988;259(10):1520-1524.

6. Mokdad AH, Ford ES, Bowman BA, et al. Prevalence of obesity, diabetes, and obesity-related health risk factors, 2001. JAMA. 2003;289(1):76-79.

7. Benjamin ER, Dilektasli E, Haltmeier T, et al. The effects of body mass index on complications and mortality after emergency abdominal operations: The obesity paradox. Am J Surg. 2017;214(5):899-903.

8. Davenport DL, Xenos ES, Hosokawa P, et al. The influence of body mass index obesity status on vascular surgery 30-day morbidity and mortality. J Vasc Surg. 2009;49(1):140-147, 147.e1.

9. Gruberg L, Mercado N, Milo S, et al. Impact of body mass index on the outcome of patients with multivessel disease randomized to either coronary artery bypass grafting or stenting in the ARTS trial: The obesity paradox II? Am J Cardiol. 2005;95(4):439-444.

10. Hutagalung R, Marques J, Kobylka K, et al. The obesity paradox in surgical intensive care unit patients. Intensive Care Med. 2011;37(11):1793-1799.

11. Mullen JT, Davenport DL, Hutter MM, et al. Impact of body mass index on perioperative outcomes in patients undergoing major intra-abdominal cancer surgery. Ann Surg Oncol. 2008;15(8):2164-2172.

12. Mullen JT, Moorman DW, Davenport DL. The obesity paradox: body mass index and outcomes in patients undergoing nonbariatric general surgery. Ann Surg. 2009;250(1):166-172.

13. Perka C, Labs K, Muschik M, Buttgereit F. The influence of obesity on perioperative morbidity and mortality in revision total hip arthroplasty. Arch Orthop Trauma Surg. 2000;120(5-6):267-271.

14. Gruberg L, Weissman NJ, Waksman R, et al. The impact of obesity on the short-term and long-term outcomes after percutaneous coronary intervention: the obesity paradox? J Am Coll Cardiol. 2002;39(4):578-584.

15. Arabi YM, Dara SI, Tamim HM, et al. Clinical characteristics, sepsis interventions and outcomes in the obese patients with septic shock: an international multicenter cohort study. Crit Care. 2013;17(2):R72.

16. Caan BJ, Meyerhardt JA, Kroenke CH, et al. Explaining the obesity paradox: the association between body composition and colorectal cancer survival (C-SCANS Study). Cancer Epidemiol Biomarkers Prev. 2017;26(7):1008-1015.

17. Galyfos G, Geropapas GI, Kerasidis S, et al. The effect of body mass index on major outcomes after vascular surgery. $J$ Vasc Surg. 2017;65(4):1193-1207.

18. Liu T, Chen J-J, Bai X-J, et al. The effect of obesity on outcomes in trauma patients: a meta-analysis. Injury. 2013;44(9):1145-1152.

19. Rios-Diaz AJ, Lin E, Williams K, et al. The obesity paradox in patients with severe soft tissue infections. Am J Surg. 2017;214(3):385-389.

20. Valentijn TM, Galal W, Hoeks SE, et al. Impact of obesity on postoperative and long-term outcomes in a general surgery population: a retrospective cohort study. World J Surg. 2013;37(11):2561-2568.

21. Hotamisligil GS. Inflammation and metabolic disorders. $\mathrm{Na}$ ture. 2006;444(7121):860-867.

22. Mohamed-Ali V, Goodrick S, Bulmer K, et al. Production of soluble tumor necrosis factor receptors by human subcutaneous adipose tissue in vivo. Am J Physiol. 1999;277(6):E971E975.

23. Valentijn TM, Galal W, Tjeertes EK, et al. The obesity paradox in the surgical population. Surgeon. 2013;11(3):169-176.

24. Brown CVR, Neville AL, Rhee P, et al. The impact of obesity on the outcomes of 1,153 critically injured blunt trauma patients. J Trauma. 2005;59(5):1048-1051.

25. Choban PS, Weireter LJ Jr, Maynes C. Obesity and increased mortality in blunt trauma. J Trauma. 1991;31(9):1253-1257.

26. Diaz JJ Jr, Norris PR, Collier BR, et al. Morbid obesity is not a risk factor for mortality in critically ill trauma patients. $J$ Trauma. 2009;66(1):226-231.

27. Ditillo M, Pandit V, Rhee P, et al. Morbid obesity predisposes trauma patients to worse outcomes: a National Trauma Data Bank analysis. J Trauma Acute Care Surg. 2014;76(1):176179.

28. Duane TM, Dechert T, Aboutanos MB, et al. Obesity and outcomes after blunt trauma. J Trauma. 2006;61(5):12181221.

29. Evans DC, Stawicki SPA, Davido HT, Eiferman D. Obesity in trauma patients: correlations of body mass index with 
outcomes, injury patterns, and complications. Am Surg. 2011;77(8):1003-1008.

30. Glance LG, Li Y, Osler TM, et al. Impact of obesity on mortality and complications in trauma patients. Ann Surg. 2014;259(3):576-581.

31. Neville AL, Brown CVR, Weng J, et al. Obesity is an independent risk factor of mortality in severely injured blunt trauma patients. Arch Surg. 2004;139(9):983-987.

32. Newell MA, Bard MR, Goettler CE, et al. Body mass index and outcomes in critically injured blunt trauma patients: weighing the impact. J Am Coll Surg. 2007;204(5):10561064.

33. Olufajo OA, Yorkgitis BK, Cooper Z, et al. How long should we fear? Long-term risk of venous thromboembolism in patients with traumatic brain injury. J Trauma Acute Care Surg. 2016;81(1):71-78.

34. Aune D, Sen A, Norat T, et al. Body mass index, abdominal fatness, and heart failure incidence and mortality: a systematic review and dose-response meta-analysis of prospective studies. Circulation. 2016;133(7):639-649.

35. Wilson PW, D'Agostino RB, Sullivan L, et al. Overweight and obesity as determinants of cardiovascular risk: the Framingham experience. Arch Intern Med. 2002;162(16):18671872.

36. Young T, Skatrud J, Peppard PE. Risk factors for obstructive sleep apnea in adults. JAMA. 2004;291(16):2013-2016.

37. Lv W, Li S, Liao Y, et al. The 'obesity paradox' does exist in patients undergoing transcatheter aortic valve implantation for aortic stenosis: a systematic review and meta-analysis. Interact Cardiovasc Thorac Surg. 2017;25(4):633-642.

\section{Disclosures}

The authors report no conflict of interest concerning the materials or methods used in this study or the findings specified in this paper.

\section{Author Contributions}

Conception and design: Benjamin, Cone, Demetriades. Acquisition of data: Cone, Alfson. Analysis and interpretation of data: Benjamin, Cone, Alfson. Drafting the article: Benjamin, Cone, Demetriades. Critically revising the article: Benjamin, Cone, Demetriades. Reviewed submitted version of manuscript: all authors. Approved the final version of the manuscript on behalf of all authors: Benjamin. Statistical analysis: Alfson. Study supervision: Benjamin.

\section{Supplemental Information Previous Presentations}

This study was presented as a podium presentation at the American College of Surgeons Clinical Congress, Neurosurgery Session, San Diego, CA, October 2017.

\section{Correspondence}

Elizabeth R. Benjamin: Keck School of Medicine, University of Southern California, Los Angeles, CA. elizabeth.benjamin@med. usc.edu. 